\title{
O libertino e os usos do passado antigo: ensaio sobre a relação de Hancarville com o passado Romano (1780)
}

\author{
The libertine and the uses of the ancient past: essay on Hancarville's relationship with \\ the Roman past (1780) \\ Alexandre Cozer \\ https://orcid.org/0000-0002-7802-0023 \\ Colégio Suíço-Brasileiro de Curitiba
}

\begin{abstract}
Resumo: Pierre-François Hugues, ou Barão de Hancarville, foi um antiquarista dedicado ao estudo de cerâmicas cujo trabalho foi desenvolvido sobretudo na baía de Nápoles, no século XVIII, quando se começava a escavar Pompeia e Herculano. Embora esse autor tenha uma obra de relevância para os estudiosos de cerâmica da Antiguidade Clássica, Hancarville também foi autor de obras menos técnicas dedicadas ao estudo de monumentos falsos e dos hábitos sexuais mais curiosos dos antigos Romanos. Nesse artigo, intencionamos realizar um estudo sobre a maneira como o autointitulado Barão se apossava do passado Clássico, em obras falsas e de caráter libertino, para gerar uma reflexão que atingia também o seu presente. Para tanto, empreenderemos, primeiro, uma discussão sobre os estudos de Usos do Passado no Brasil e de que maneiras nos vale se aproximar dessa forma de pensar a Arqueologia e a História. Em um segundo momento, buscaremos pensar a maneira como se conforma o pensamento do estudioso sobre a Antiguidade e sobre a sexualidade. Intencionamos, com isso, mostrar que mesmo em se tratando de monumentos inventados, o antiquarista desenvolvia um pensamento fundamentado na leitura de documentação e na análise próxima à historiografia. Que seu pensamento tenha ficado de lado, ou que tenha influenciado unicamente teorias mais críticas sobre o passado, aponta para algumas das exclusões com as quais se formou a disciplina de História Antiga.
\end{abstract}

Palavras-chave: Usos do Passado. Libertinos. Arqueologia.

Abstract: Pierre-François Hugues, or Baron d'Hancarville, was an antiquarian dedicated to the study of pottery who worked long around the bay of Naples during the XVIII century, when Herculaneum and Pompeii were being discovered. Even though this is a relevant author to those engaged in the study of Classical Pottery, Hancarville was also the writer of less technical interpretations, like the two books dedicated to study false monuments and ancient's sexual practices. In the present paper, we intend to study the way in which the self-entitled Baron, on those two fallacious books, related to the Classical Past to generate a way of thinking that would aim also his own present. Thus, we will develop, first of all, a debate with some works on the Uses of the Past to clarify how do we relate to this kind of thinking in both History and Archaeology. Secondly, we will show the method used by the author to study and create his own thinking on Antiquity and its sexuality. Our goal is to show that, even discussing false monuments, this antiquarian had his own and well based thinking, supported by many documents and close to the main academic historical analysis. The fact that he has been left behind, or that he has influenced mostly other critical philosophers and writers, helps elucidate also on which exclusions the academic Ancient History was built.

Keywords: Uses of the Past. Libertines. Archaeology.

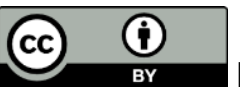

Esta obra está licenciada sob uma Creative Commons - Atribuição 4.0 Internacional 


\section{Introdução}

A Antiguidade grega e romana nem sempre foi percebida pelos seus estudiosos como exemplo de grandeza imperial ou como justificativa para a dominação imperialista e colonial das potências europeias, como parece ter acontecido principalmente a partir da segunda metade do século XIX. Plenos de material poético e filosófico de diferentes e, por vezes, contraditórias escolas de pensamento sobre a natureza, a ética e a vida, os textos latinos e helênicos foram também material de inspiração para pensamentos e estéticas contestatórios da tradição de pensamento moderna e cristã. No caso de PierreFrançois Hugues D'Hancarville, pensador importante para o surgimento da Arqueologia e para a História Antiga, a leitura sobre os amores, os desejos e as práticas sexuais dos antigos, em um momento de questionamento da moral oitocentista, serviram para inspirar, por um lado, uma atitude de compreensão com as práticas eróticas do passado e, por outro, uma atitude de revisão da moral que era defendida em seu tempo pelas igrejas e pelos Estados que surgiam. Tal questionamento da sexualidade, aparece, sobretudo nas obras que são, aqui, nossos objetos de estudo: Monumentos para a vida dos doze césares, de 1782, e Monumentos para o culto secreto das matronas romanas, de 1784.

Nesse trabalho, partiremos da perspectiva de usos do passado para investigar de que maneiras Hancarville se apropria dos textos literários e historiográficos da antiga Roma: temos o objetivo de demonstrar que, apesar de normalmente percebermos a associação da Antiguidade com os poderes institucionais, ela também foi o motivo de um pensamento lúdico e da tentativa de criar mundos e modos de vida outros. Para tanto, em um primeiro momento do texto, explicaremos com que tipo de estudo de usos do passado nos associamos. De um lado, empreenderemos uma tentativa de narrar essa apropriação da Antiguidade sem realizar, ao libertino, reprovações ou correções. Perceberemos que a mera investigação da interpretação do arqueólogo nos possibilita evitar um tipo de narrativa que aponte para a possibilidade de encontrar um passado objetivo ou real. De outro lado, buscaremos pensar a história a partir de uma pluralidade de vozes - pluralidade da qual o próprio pensamento de Hancarville fora excluído.

Em um segundo momento de nossa redação, analisaremos propriamente o pensamento desenvolvido por esse antiquarista que já criava as primeiras metodologias e formas de análise da Arqueologia e do estudo das cerâmicas. Sua interpretação literal dos textos antigos, aceitando como dados de realidade as narrativas de historiadores, satiristas e poetas do passado, o levaram a sustentar um pensamento que buscava compreender a origem do comportamento sexual dos romanos, por vezes visto como exagerado. Apesar de suas reflexões não serem desprovidas de valor, esse escritor tem sido retirado das páginas da história do pensamento sobre o passado romano. Concluiremos, sem grandes delongas sobre Hancarville, que relê-lo possa também fazer parte de um processo de abrir a historiografia para outras tradições e maneiras de olhar e de usar do passado.

\section{O passado e os Usos do Passado}

Se História e Arqueologia são, por excelência, as disciplinas que se preocupam com o passado das sociedades humanas, apesar das diferenças de objetos, a partir da segunda metade do século $X X$ ambas têm sofrido algumas revisões semelhantes. Talvez um ponto comumente discutido pelas áreas seja os moldes ou a forma como lidamos com os ocorridos que se tornam, para nós, objetos de estudos. Entretanto, se 
em História esse revisionismo atingiu mais alguns dos conceitos e interpretações da disciplina, em Arqueologia a atenção parece ter-se voltado não apenas para a reconsideração de conceitos da própria disciplina, mas também para o modo como as construções narrativas oriundas dos estudos da cultura, ou mesmo como a própria cultura material em seu valor simbólico, poderia servir de instrumento no presente. A concepção de uso do passado, que hoje e sobretudo no Brasil já se insere nos debates dentro da historiografia, marca no conceito a noção de que o passado possa ter um valor utilitário.

Don Fowler (1987), em importante texto para o tema, dedica-se a pensar como a Arqueologia e o passado material pode ter usos culturais em diferentes momentos e sociedades. O autor analisa sobretudo experiências históricas do México, da GrãBretanha e da República Popular da China. O olhar sobre os três momentos históricos diversos, entretanto, se estabelece por um interesse em comum: nos três casos, malgrado diferenças nos sistemas de governo, o passado serviu de motivo para legitimar estabelecimentos nacionais. Tais momentos também indicam para Fowler que o estudo arqueológico deve tomar muito cuidado ao se debruçar sobre o passado para evitar de sucumbir às experiências e interesses históricos do presente, ainda que isso pareça quase inevitável. O conhecimento dos usos deve, segundo o autor, também criar nos novos historiadores uma consciência crítica:

In seeking accessibility to the 'real' past, archaeologists must continue to be aware of the influences of ideologies and values on their own professional culture, and hence on how they use the past. One of the salubrious results of the 'new' archaeology has been the insistence that hypotheses and 'linking arguments' be rigorously framed and scrutinized. The emerging critical discussion of archaeological analyses and interpretations carry this insistence on rigor a step further ${ }^{1}$.

No estudo dos usos do passado, portanto, percebemos não apenas uma preocupação com a crítica desses usos, como também uma atitude de reflexão sobre a própria disciplina, suas bases epistemológicas e o método com o qual se acessa o passado. Na perspectiva de Fowler, ainda encontramos uma concepção que tem sido criticada por alguns estudiosos 2 : a de que se acredite, ainda, na possibilidade de acesso a um passado remoto mas em estado puro. Embora tal concepção possa ser um problema tanto da perspectiva dos usos do passado quanto da perspectiva dos estudos de recepção - esse último muito mais influenciado pela concepção ontológica de Heidegger $^{3}$ - queremos, antes de realizar nossas análises históricas, apresentar duas soluções para esse problema e, ao mesmo tempo, que esclarecer sobre nosso próprio modo de operar no estudo de duas das obras mais tardias de Pierre-François Hugues

\footnotetext{
${ }^{1} \mathrm{Na}$ busca por acesso ao 'verdadeiro' passado, arqueólogos devem permanecer atentos às influências das ideologias e valores em sua própria cultura profissional, e sobretudo ao modo como usam do passado. Um dos resultados mais salutares da 'nova' arqueologia foi a insistência em que hipóteses e 'argumentos de ligação' sejam rigorosamente enquadrados e escrutinados. A emergente discussão crítica das análises e interpretações arqueológicas leva a atenção ao rigor um passo adiante. (Essa, como todas as traduções, é nossa).

${ }^{2}$ Como exemplo de uma perspectiva menos crente em um passado puro, ver Funari, Silva \& Garraffoni, (2017).

${ }^{3}$ Como também apontado por Derrida (2017), a distinção de Heidegger entre ontos e ente cria a impressão de um ser originário, sempre a se perder, mas em estado possivelmente puro. Quando mencionamos tal concepção nos estudos de recepção, queremos com isso apontar para a concepção de origem acessível presente em tais estudos, sobretudo em obras mais clássicas como a de Jauss (1994), fundador da estética da recepção. Em estudos mais recentes, usos do passado e recepção têm tendido a rever a ideia de que houvesse um passado real ou de que a recepção o tenha relido com distorções.
} 
ou Barão de Hancarville.

Em primeiro lugar, queremos repetir o que apontam Funari, Silva e Garrafoni: apesar de uma possível manutenção da noção de que existiria um passado certeiro, a perspectiva dos usos do passado ainda assim desenvolve um olhar sempre crítico para o próprio estudo daquilo que nos precede. Vimos como Fowler também entende que tais estudos devem tornar-nos mais críticos com relação aos nossos métodos e conceitos, e com efeito, encontramos grande literatura a chamar atenção para a importância dos usos imperialistas do passado na conformação de noções fundamentais da disciplina. Como exemplo, Bettina Arnold (1990) demonstra como a arqueologia pré-histórica na Alemanha é, até hoje, estabelecida sobre conceitos e estudos que foram permitidos e influenciados pelo regime nazista.

No Brasil, estudiosos têm se debruçado sobre momentos tanto de formação das disciplinas, quanto sobre usos mais propriamente políticos da arqueologia e do passado clássico. Tais estudos são, em muito, debitários do trabalho de Funari, quem desenvolveu uma preocupação de inspiração pós-colonial na arqueologia histórica, iniciando os trabalhos sobre os usos do passado no Brasil de forma associada a uma concepção de Arqueologia Pública e de crítica ao estudo do passado como um estudo objetivo (HINGLEY, 2017). Nessa senda, Rafael Rufino (2013) se debruça sobre os usos feitos pelo General Franco, na Espanha, não apenas no sentido de comemorar o bimilenário do nascimento de Augusto, mas também de utilizar dessa comemoração como meio de associar tanto sua imagem com a do imperador romano, quanto seu governo com o governo de Mussolini na Itália, o qual também fizera uso da imagem de Otávio para seu próprio governo. Fábio Hering (2005) demonstra como intelectuais e arqueólogos clássicos da Alemanha Nazista buscaram, na História da Grécia Antiga que construíam, não apenas narrativas que confirmassem a origem ariana de seu povo como também símbolos, como a própria suástica, nos quais basear essa trama e sustentar suas identidades. Também José Geraldo C. Grillo (2018) estuda as políticas com relação à arqueologia Clássica no contexto da independência e fundação do Estado nacional da Grécia. Nesse momento, a nação grega se inventa excluindo o passado turco e se aproximando, quase que exclusivamente, da história da Grécia Antiga e do Helenismo como meio de justificar também uma maior proximidade com os países e a ciência das outras potências europeias.

Os estudos dos usos do passado no Brasil, têm se dedicado sobretudo a pensar os momentos em que, com as disciplinas da História e da Arqueologia surgindo na academia, criaram-se narrativas sobre a história que tinham intenção de sustentar projetos de governo e de domínio, ou mesmo a colonização. O que nos interessa metodologicamente é que, em tais estudos, não percebemos a tentativa dos estudiosos de comparar os diversos usos do passado com outras narrativas elegíveis como mais cientificamente precisas. O que interessa a esses arqueólogos e historiadores brasileiros é, mais exclusivamente, a importância e a forma que tomou a concepção do passado em determinados contextos históricos do que uma comparação específica com o que poderia ser pensado como o passado vivido. Rufino não conclui sobre como teria sido a Roma de Augusto, nem Hering sobre a efetiva origem da suástica ou os povos arianos. Tais trabalhos, redigidos de modo crítico, tendem, portanto, a demonstrar como certas concepções de História verdadeira e de objetividade estavam, em verdade, associadas com movimentos políticos nacionalistas que resultaram em noções estáticas de cultura tanto para o século XIX e XX quanto para o estudo do passado Grego e Romano. 
Em nosso estudo, também buscaremos não apontar conclusões sobre a verdade do passado antigo, mas apenas demonstrar que tipo de leitura de documentação e que tipo de relação com a Antiguidade estabeleceu-se na obra desse pensador de roupagem libertina. Mas pensar uma voz que, como a de Hancarville, foi soterrada nas bibliotecas mais sombrias nos leva também à questão sobre como se organiza o conhecimento desse passado e a escrita sobre as interpretações dele. Acreditamos que essa segunda questão nos permita elaborar uma outra saída para não tornar os estudos dos usos do passado um que mantenha, a contrapelo, uma concepção em algo cientificista e objetiva da História. E essa solução é também inspirada pela Arqueologia.

Dentro desse campo científico, tem-se desenvolvido uma preocupação cada vez maior com a pluralização das narrativas históricas. Os arqueólogos têm destinado maior atenção - sobretudo a partir do surgimento de movimentos sociais e da assunção de que a parcialidade é inevitável quando se escreve sobre o passado - para as partes interessadas (stakeholders) na escrita sobre o passado e na cultura material. Assim, Barbara Little (2007) demonstra, em seu livro, como a arqueologia não deve ter em conta apenas resultados alcançados com métodos científicos, mas também a comunidade, para quem esse passado também importa, deve ser ouvida no momento da criação do conhecimento. Tal movimento tem a intenção de se estabelecer um vínculo entre a população local e os monumentos ou a cultura material encontrados ou estudados pela academia. Para a autora, essa atitude não apenas resolve o problema da objetividade do passado, como também transforma o estudo dele em algo mais útil: o passado permite que diferentes comunidades e interesses se conectem, busquem uma relação e convivam a partir de suas memórias, ele existe a partir do interesse público:

On the other hand, the empowering uses of the past relate to the creation of bridging social capital which acts across social divides to pull people together. Given people's often inward-looking perceptions of history, what is the role of heritage professions in public outreach about the past? The role of social history, whether historical or historical archaeological, is to connect everyday experience to the larger structures of major social change. Historical archaeology can provide, or at least suggest, the connections that individuals and families might not make for themselves ${ }^{4}$. (LITTLE, 2007, p. 168-169)

Esse problema não se restringe, no entanto, à arqueologia, mas atinge o estudo do passado de um modo geral. A percepção dos diversos interesses e a busca de construir uma narrativa maior e mais engajada com as diversas comunidades sociais, para Little, pode então auxiliar na própria vivência de uma sociedade mais democrática. O mesmo problema pode ser transportado da construção de narrativas sobre um sítio arqueológico e levado para a própria narrativa textual na qual se insere também o pensamento historiográfico. Rosemary Joyce, em capítulo que reflete propriamente sobre o problema da escrita, chega a uma solução baseada na teoria da multivocalidade de Bakhtin. Para a autora, ao escrevermos sobre o passado devemos buscar contemplar as diferentes vozes que falam sobre ele, e esse seria o primeiro passo para

\footnotetext{
${ }^{4}$ Por outro lado, o uso empoderador do passado se relaciona com a criação de capital cultural associativo, o qual age além das barreiras sociais para aproximar as pessoas. Dada a comum percepção autocentrada da história, qual será o papel das profissões que trabalham com o patrimônio na publicização do passado? O papel da história social, seja História ou Arqueologia Histórica, é conectar a experiência cotidiana a uma maior estrutura de importantes mudanças sociais. A arqueologia histórica pode suprir, ou ao menos sugerir, as conexões que indivíduos e famílias podem não realizar sozinhos.
} 
evitar que uma interpretação particular, sempre representativa de certos interesses aos quais a própria academia se associa, possa prevalecer enquanto imagem precisa de uma temporalidade:

Writing archaeology is self-evidently more than a form of neutral representation of facts, arranged in a storyline that makes some kind of sense. It is an act of communication, with its own rhetorical forms shaped by the orientations of writers to their assumed audiences. By claiming a position in the text as narrator, many contemporary historical archaeologists introduce into their texts a specific speaking voice, the first step in constructing polyphony, the sound of multiple voices ${ }^{5}$. (JOYCE, 2006, p. 55)

Joyce nos convida, portanto, a trazer, na própria escrita sobre o passado, uma visão menos unilateral. $\mathrm{E}$, com efeito, esse é também um dos objetivos de nosso texto. Por um lado, voltar a atenção para a obra de Barão de Hancarville consiste em evitar o pensamento sobre a arqueologia ou a história científica - Hancarville as precede em alguns anos, embora seu trabalho possa ser considerado importante para a fundação de certas concepções arqueológicas. Estudar esse autor e sua obra é, antes, debruçarse sobre algo que ficou de fora da academia. Por outro lado, as rápidas digressões que faremos por interpretações mais recentes sobre a História de Roma e das práticas sexuais nesse contexto não têm, aqui, a intenção de demonstrar os erros ou acertos da interpretação desse libertino. Ao contrário, intencionamos que essas outras vozes apenas nos ajudem a perceber algumas das características da leitura que Hancarville fazia da documentação que estudava e da que pretensamente estudava. Nosso objetivo, portanto, não é o de demonstrar quão certa ou errada estava a concepção de passado do escritor, mas apontar os motivos e o contexto que o incentivaram a escrever obras tão curiosas. Que seus trabalhos tenham sido deixados de lado pela historiografia e até mesmo pela leitura psicanalítica sobre a sexualidade, meramente indica algumas das exclusões de vozes com as quais se fundou o estudo da Antiguidade Clássica. Reler esse libertino talvez seja pluralizar um pouco mais essas vozes.

\section{Hancarville, sua obra e o sexo na Antiguidade}

Pierre François Hugues, que se auto denominou Barão de Hancarville, nome pelo qual ele é mais conhecido, nasceu em 1719 e morreu em 1805. Intelectual reconhecido, desde muito cedo, pelo seu interesse pela Antiguidade e bom conhecimento do Latim, do Grego e da literatura Clássica, Hancarville trilhou um caminho cheio de desvios. Depois de crescer na França, ele passou pelas cortes de Portugal e da Suíça antes de fixar-se, fugido, em Nápoles no ano de 1763. Foi nessa região que conheceu intelectuais de diversas partes do mundo que vinham ali com o interesse de descobrir as obras Antigas e as maravilhas de Pompéia e de Herculano que eram desenterradas e passavam a ser estudadas pelo mando da família real dos Bourbons.

Nesse contexto, a dinastia dos Bourbons operava de maneira um pouco contraditória com relação à produção do conhecimento: por um lado, desde 1738

\footnotetext{
${ }^{5}$ Escrever arqueologia histórica é, evidentemente, mais do que uma forma neutra de representação dos fatos, organizados em uma linha narrativa que faz algum tipo de sentido. É um ato de comunicação, com seus próprios padrões retóricos conformados pelas orientações de escritores a suas supostas audiências. Ao deixar clara a própria posição de narrador em um texto, muitos arqueólogos contemporâneos introduzem em seus textos uma voz de fala específica, o primeiro passo na construção da polifonia.
} 
Pompeia e Herculano foram decretadas tesouros reais; em 1755, e só eram escavadas por aqueles que se associavam à coroa, limitando o conhecimento da Antiguidade àqueles que se associavam ao poder real e seus interesses. Por outro lado, esse reinado financiava a vinda de intelectuais, criando o Museo Ercolanese e divulgando conhecimento sobre a Antiguidade, o que fez com que muitos intelectuais livres e de outros países fossem atraídos pela região de Nápoles e tomassem seu tempo com o estudo de monumentos arqueológicos de maneira menos oficial - como é o caso de nosso pensador. Foi nesse local que se definiram os rumos de inúmeras ciências atuais, desde os estudos da arqueologia, às técnicas de escavação, às primeiras discussões sobre os museus e mesmo até o uso da Antiguidade como prova de poder e valor de uma dinastia e de um estado - dado que os Bourbons faziam uso desse poder sobre a Antiguidade como expressão do valor de sua coroa.

Por motivo desse afloramento de pensamento e discussão é que autores chegam a sugerir que devêssemos pensar em Nápoles como outro capítulo do movimento do iluminismo (SCHNAPP, 2000; ECHLIN, 2014; MONOD, 2013). Se isso é possível, certamente Hancarville ocuparia um papel importante nesse capítulo. Sua obra principal, que narra as antiguidades e os vasos da coleção de William Hamilton, e que foi publicada em quatro volumes, consiste em um importante trabalho para se pensar nos artefatos da Antiguidade. $\mathrm{O}$ autor analisa os vasos que, posteriormente, viriam a constituir a maior parte da coleção de Antiguidade do British Museum (a coleção de Hamilton somava quase 8 mil itens entre vasos, terracotas, baixos-relevos, prataria e numismática). É interessante notar que, nesse processo de análise, Hancarville organiza um pensamento que é responsável por contribuir tanto com a Arqueologia quanto com a História da Arte. De acordo com Carabelli (1996), é esse o estudioso que inventa o modo de representação atual da arte dos vasos, recortando as imagens da cerâmica. Esse também cria modos de desenhar a própria cerâmica, mostrando as medidas; de diferenciar os vasos gregos, etruscos e italiotas - que por muito tempo eram pensados enquanto etruscos - e desenvolve um trabalho histórico sobre como mudam essas peças e como elas nos permitem o acesso ao quotidiano do passado. Nesse ponto, Hancarville começa a se interessar também pela cultura cotidiana, desviando o foco de assuntos puramente políticos ou técnicos e adentrando sobretudo o campo do religioso.

Mas se a história do século XVIII se relaciona com o iluminismo, a de Hancarville parece, quanto a esse pensamento, um pouco mais subterrânea. Em primeiro lugar, o estudioso não tem acesso à Antiguidade por via da coroa de Nápoles, mas por via da associação com Hamilton. Em segundo lugar, Hancarville parece ter uma evidente ligação com o pensamento libertino (Carabelli, 1996) o qual desenvolveu um pensamento em boa parte diferente da filosofia do iluminismo que, ainda hoje, influencia o raciocínio científico. Com efeito, a noção de libertino deriva da palavra latina para liberto e servia para designar escravos libertos ou convertidos. O termo, entretanto, já parecia ser usado na França para designar pessoas de comportamento reprovável ou intelectuais de concepção crítica desde os séculos XVI e XVII.

De acordo com Jacques Prévot (1998), esse movimento, no século XVII se caracteriza antes pela presença de intelectuais de raciocínio crítico ao estado ou ao pensamento. Por um lado, tais pensadores vinculavam-se sempre à Antiguidade e traziam dela tradições filosóficas que não correspondiam ao aristotelismo que imperava na Idade Média e nas academias e universidades do período. Com isso, a redescoberta dos textos antigos deu origem a novas tradições como a do atomismo materialista de 
Epícuro ou a do ceticismo pirroniano. Em que pese esses intelectuais se encontrarem de fora dos círculos de poder do conhecimento na primeira modernidade, seus trabalhos foram influentes e Prévot considera mesmo que teriam importado para o próprio surgimento do método cartesiano.

Entretanto, a libertinagem era a procura de uma outra forma de pensamento. Nesse contexto em que romances libertinos eram escritos, novas formas de culto cristão eram estabelecidas criticando a autoridade da igreja católica e a ética medieval. Mas também na filosofia se questionava o princípio unicamente divino de organização e regência do mundo. Pascal, por exemplo, colocava em paralelo com o divino a existência de princípios naturais que determinavam a essência humana. Deixa-se de perceber o homem como o grandioso animal que se assemelha a deus e, Para Prévot:

À force de définir plus implacablement les infirmités de la condition humaine, c'est la nature humaine même dont on allait devoir remettre en chantier la conception. La tradition chrétienne voyait, selon le mot de la Bible, en chacun des êtres humains l'image de Dieu [...] On s'éloigne de toute apologie de la grandeur de l'homme pour faire le recensement de ses misères et de ses impuissances ${ }^{6}$. (PRÉVOT, 1998, p. LVI - LVII)

Figura 1 - Cena 7 do Monumens à la vie de XII Césars

$$
\text { N.7, }
$$

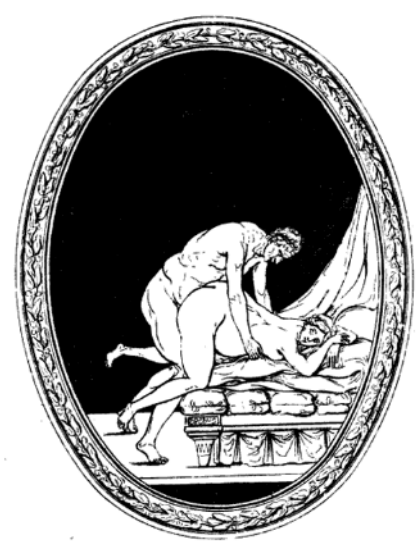

Fonte: Hancarville, 1780 , p. 32

Assim, tal libertinagem surge de um espírito de revisão não apenas filosófica, mas também de pluralização das noções sobre o mundo e do questionamento sobre a própria natureza humana.

No século XVIII, entretanto, essa filosofia passará também a envolver um pensamento do corpo e do ato sexual enquanto algo que define a experiência do pensamento. De modo certamente cômico, a máxima horaciana do iluminismo e de Kant, sapere aude, será transformada pelos filósofos em fornicare aude ut sapias, ou

\footnotetext{
${ }^{6} \mathrm{Na}$ procura de definir mais implacavelmente as enfermidades da condição humana, é a própria concepção da natureza humana que se colocará em questão. A tradição cristã via, segundo a Bíblia, em cada ser humano a imagem de Deus [...] E os intelectuais se distanciam de toda apologia à grandeza do homem para fazer o recenseamento de suas misérias e fraquezas.
} 
seja: em lugar de ousar conhecer, ouse fornicar para que conheças. Eis a forma mais conhecida da libertinagem (NOVAES, 1996).

Tais intelectuais, entretanto, não dispunham de uma visão única sobre o corpo ou o sexo e, antes de estabelecerem um acordo sobre o assunto, o investigavam de modo livre. O orgasmo ou o prazer eram formas de se perceber os limites da virtude, do corpo, mas também de se experimentar sensações, de conhecer o certo e o errado (NOVAES, 1996). A imagem do sadismo é apenas uma das maneiras que os libertinos encontraram para solucionar o problema do conflito entre a natureza e a moral - e aqui, a noção de natureza humana mantém-se importante no pensamento libertino, sendo investigada e pensada enquanto uma dimensão inescapável da vida. De acordo com Bento Prado Jr. (1996), para esses pensadores, passar pelo corpo e pela experiência o pensamento significava também buscar o diferente ou o exterior à sua cultura: esses estudiosos e literatos transformavam o corpo na própria condição pela qual a reflexão surge. Assim, descobriam formas de riso sarcástico contra outros autores contemporâneos e os hábitos modernos, experimentavam o sexo, buscavam referências alternativas.

Como podemos perceber, a relação entre ideia e corpo colocada pelos libertinos não chega a desenvolver um pensamento sobre a sexualidade ou indicar caminhos diretos para o modo como o sexo crie sujeitos ou identidades. Por esse motivo, nosso estudo das obras de caráter mais sexual de Hancarville, seguindo uma sugestão feita por Carabelli (1996), passam antes por tentar entender algumas das questões elaboradas pelo historiador a partir de suas leituras da documentação antiga e de alguns elementos presentes nos pensadores libertinos do que pela tentativa de descobrir uma sexualidade para o século XVIII. Com efeito, nesse momento tanto a arqueologia não era uma ciência, quanto o próprio sexo parecia ser concebido antes por uma ars sexualis como aponta Foucault (2011).

A ideia de arte talvez ajude a entender nossa documentação. Selecionamos duas obras que Hancarville publicou na seguinte ordem: primeiro, a coleção de Monumentos para a Vida dos Doze Césares, e em seguida os Monumentos para o Culto Secreto das Damas Romanas. A obra sobre os césares teria sido originalmente publicada, de acordo com Davis (2001), em 1771; no entanto, as edições que acessamos delas são, ambas, dos anos 1780, época em que teriam circulado diversos países na Europa e ganhado várias reimpressões - o que prova um certo sucesso das obras. Nosso proto-arqueólogo descobrira a influência que a divulgação de certas antiguidades poderiam ter na cultura europeia desde a publicação de estudos sobre vasos de Hamilton (Schütze, 2015; Huwiler, 2015), os quais alcançaram grande sucesso e influenciaram tanto pintores quanto ceramistas do continente. Entretanto, se Hancarville tem papel relevante para a história da arqueologia e do estudo da cerâmica antiga, as obras que nos propomos estudar diferem em muito de seus estudos mais famosos por nos exporem medalhas e camafeus de invenção do próprio arqueólogo, criados por artistas também imaginários.

Os livros teriam sido feitos na llha de Capri, local muito referenciado por libertinos que, lembrando o texto de Suetônio sobre a vida de Tibério, pensavam na ilha ainda como um lugar de depravação. A própria obra de Hancarville, portanto, surge enquanto um jogo com o passado antigo e interesses da sua modernidade. A exemplo da mera representação dos camafeus que se apresentam, podemos perceber neles tanto uma evidente inspiração em obras de cunho erótico antigos quanto alguns padrões realizados por tradições contemporâneas de representação do sexo. Isso fica evidente 
na figura 1, do livro Monumentos à vida dos doze césares, que representa um intercurso entre Augusto e Lívia, sua mulher.

O tema representado tem certamente origem na própria arte antiga. É fácil lembrar-se, com ela, das pinturas das Termas Suburbanas de Pompeia, ou mesmo das representações parietais presentes nos lupanares. O próprio realismo da representação parece aproximar o desenho da Antiguidade. Hancarville teria entrado em contato com esse tipo de figuração durante as escavações. Entretanto, há algo também da representação das figuras eróticas do XVIII. De acordo com Darnton (1996), a literatura libertina da época representava o corpo de modo um pouco diferente. Reparamos, por exemplo, que as barrigas são mais avolumadas do que as representações romanas. Nelas, as dobras de gordura evocam um padrão francês de beleza e sensualidade: a chute des reins, ou seja, as dobras nas costas que ficavam pela altura dos rins. A posição delicada com que Lívia posiciona os braços também evoca uma sensualidade que era expressa mais pelo colo e pelos membros superiores do que efetivamente pelas pernas e coxas, embora essas também sejam avantajadas. Se é difícil verificar o quanto esses livros tinham a intenção de excitar seus leitores, é certo, entretanto, que eles correspondiam a um padrão erótico expresso nas pinturas e nas concepções populares (cf. DARNTON, 1996).

Entretanto, se os monumentos expostos pelo arqueólogo são falsos, cabe ressaltar que suas interpretações sobre a Antiguidade não eram de todo exclusas de comprovação nas fontes. O próprio nome da primeira publicação indica: "monumentos para a vida dos doze Césares" aponta para a inspiração nas biografias de Suetônio. $\mathrm{Na}$ introdução do livro, Hancarville comenta:

\begin{abstract}
Laissant aux commentateurs de Valleius Paterculus, de Suétone \& de Tacite, le soin de vérifier les fais, je les présente comme avérés \& authentiques : \&, sans me tourmenter à chercher pourquoi Pline, dans le chapitre de son histoire naturelle, où il parle des excellens artistes en tous genres, ne fair pas mention de la plupart des graveurs que je cite, je me contente de présenter des monumens de leur habilité, qui prouvent assez que Pline ne s'est pas piqué de la plus grande exactitude ${ }^{7}$. (sic. D'HANCARVILLE, 1782, p. iv)
\end{abstract}

Como podemos perceber, esse pós-antiquarista anuncia sua inspiração nas obras de escritores antigos e, mais do que isso, também anuncia que não se aterá ao estudo dessas obras de maneira crítica. Sua escrita, com algum humor, chega a criticar Plínio o velho por não ter dedicado algum capítulo ao estudo específico dos artistas de camafeus e de medalhas. Seu grande conhecimento do passado, entretanto, é marcado por uma atenção pura à documentação. Em interpretações mais recentes da historiografia, têm-se buscado pensar os textos dos historiadores, e em especial as narrativas de Suetônio, como formas de criticar os imperadores e ressaltar sua depravação (PUCCINI, 2007), ou mesmo perceber essas críticas como formas de rir que talvez estivessem ligadas com concepções apotropaicas da cultura romana ou mesmo com a necessidade de se conter a grandiosidade dos imperadores (MINOIS, 2007). Por fim, alguns estudos de gênero têm empregado do conceito de regime de gênero para pensar a possibilidade de que os excessos sexuais pudessem configurar

\footnotetext{
${ }^{7}$ Deixando aos comentadores de Valério Paterculo, de Suetônio e de Tácito a preocupação de verificar os fatos, eu os apresento como certos e autênticos: e, sem me desgastar na procura do motivo de Plínio, em seu capítulo da história natural que discursa sobre os excelentes artistas de todos os gêneros, não fazer menção da maior parte dos gravuristas que cito, me contento em apresentar os monumentos de suas habilidades que provam que Plínio não é tomado da maior exatidão.
} 
verdadeiras performances levadas a cabo pelos imperadores para marcar a diferença entre eles e o resto da população: a permissividade, então, seria marca do poder imperial (PEREIRA \& ESTEVES, 2016).

No caso de Hanrcarville, entretanto, se estabelece um tipo de leitura que podemos interpretar como literal. Seu método de análise consiste em separar os trechos que mencionam proezas sexuais dos imperadores nas obras dos historiadores antigos e criar uma breve narrativa sobre o que teria acontecido nas experiências do passado. Embora o texto pareça servir para ilustrar o monumento, sabemos que, dada a falsidade dos camafeus, ocorreria o contrário: são esses falsos elementos materiais que ilustram os textos antigos. Para mantermo-nos na vida de Augusto, na figura 6 o oitocentista comenta as histórias de amor entre Augusto e César, apontando para o fato de que Otávio teria se servido da volúpia do tio para conseguir seu Império e ressalta, citando Suetônio sem o informar, que os romanos da época se diziam "uidisne ut cinaedus orbem digito temperat?" (Suet. Aug., 68,1,12), ou seja, "não vês que um cinedo comanda o mundo com um dedo?". A palavra Cinaedus, aqui, podendo indicar tanto o comportamento homoerótico do imperador, quanto sua posição enquanto passivo de Augusto ou mesmo sua depravação e forte desejo sexual.

Essa interpretação literal da documentação empreendida por Hancarville poderia ser expressa por outras passagens famosas, como a ideia também presente em Suetônio de que César seria "o homem de todas as mulheres e a mulher de todos os homens". E embora estejamos diante de uma interpretação assaz literal, não podemos reduzir os recortes e reorganizações que o barão realiza nas obras antigas a uma simples transposição do passado para o presente. Como seria inevitável, esse ressurgimento dos textos antigos leva a um choque de realidade e faz com que nosso escritor moderno pense sobre a própria cultura romana. Ainda tratando da vida de Augusto e das relações dele com César, Hancarville relembra que o homoerotismo deveria ser normal para as culturas grega e romana. Ele não apenas menciona outros imperadores, como Adriano, mas também poetas importantes tais que Catulo, Virgílio, Marcial, Petrônio e Horácio que cantaram seus amores por outros homens e nem por isso deixam de ser admiráveis.

Com efeito, começamos a perceber que a dedicação do arqueólogo ao assunto do ato sexual o fez também notar esse passado enquanto diferença e motivo de questionamento para o seu presente. Se nessa primeira obra o autor já reconhece a vida dos imperadores como não-anormal, em sua segunda, os monumentos ao culto secreto das matronas (D'HANCARVILLE, 1784), ele elabora uma verdadeira reflexão sobre o lugar do sexo na cultura.

Essa segunda obra é nomeadamente preparada para servir de sequência aos monumentos da vida dos doze Césares. Entretanto, aqui, a historiografia latina ocupa um posto um pouco menor do que a literatura. Hancarville busca em obras como a Priapeia, mas também em poesias de Catulo, Virgílio, Horácio e até de Juvenal, elementos que apontem para hábitos sexuais mais específicos das mulheres romanas. Novamente aceitando tudo como realidade, Hancarville chega a repensar as próprias narrativas romanas sobre o assunto sexual, sendo ele próprio menos crítico a esses hábitos do que, por exemplo, o satirista Juvenal.

Percebemos, nessa obra, ecos da documentação antiga trabalhada pelo escritor. Ao apresentar essa segunda coleção de camafeus falsos, Hancarville retoma uma narrativa presente em autores latinos, como por exemplo Tito Lívio (Praefatio), ao afirmar que os romanos não eram entregues ao sexo e aos prazeres antes que 
conhecessem a cultura grega e as depravações da moral conhecidas por esse povo. A noção também retoma a máxima horaciana, graecia capta ferum uictorem cepit et artis intulit agresti latio (Epístulas, 2, 1), ou seja, "a Grécia, capturada, capturou seus ferozes vencedores e trouxe a arte para o agreste Lácio". Entretanto, apesar de algum julgamento negativo quanto aos costumes sexuais dos antigos expressos pela literatura e ilustrados pelos falsos camafeus, Hancarville não deixa de tornar o sexo, como vimos para os libertinos, um assunto de reflexão, dando prática ao título do historiador Robert Darnton "Sexo dá o que pensar". Na introdução, onde o escritor realiza a maior parte de suas reflexões sistematizadas sobre o assunto, lemos:

Les anciens ne regardaient pas du même œil que nous, les plaisirs de l'amour. Cette tendre union des deux sexes excitait leur vénération, parce que la religion semblait consacrer cet acte de la Nature. Leur mythologie offre \& célèbre de nombreux prodiges en amour. Jupiter, le Père des Dieux, frere \& époux de Junon, étendait encore ses conquêtes amoureuses dans tout l'univers. Leda, Europe, Danaé, Semelé, Alcmene \& mille autres charmantes mortelles, furent l'objet de ses goûts \& céderent à son pouvoir ${ }^{8}$. (D'HANCARVILLE, 1784, p. iv)

O conhecimento da mitologia e da religião dos antigos - o livro afinal trata dos cultos das matronas, ou seja, de suas relações com os deuses - leva o autor a perceber que alguns atos reprováveis pelos modernos não o eram pelos antigos. Isso não significa necessariamente que essa tão pretérita cultura fosse, por ele, vista com maus olhos. Em uma posição de compreensão, Hancarville justifica as atitudes dos antigos: eles nada faziam além de imitar seus deuses, também famosos por atos sexuais lícitos e ilícitos, por entregar-se aos desejos. Mas além de justificá-lo, Hancarville o considera como um ato de natureza. Já vimos anteriormente como o século XVII e XVIII haviam começado a perceber, novamente, na natureza um princípio de organização da vida concorrente com o divino. Talvez inspirados em concepções antigas, tanto do atomismo de Epicuro, mas até mesmo do sequi natura estóico, esses pensadores poderiam analisar em impulsos sexuais também um eco dessa pulsão natural causada pelo corpo. O próprio corpo tornara-se, então, um meio de investigação da essência humana e dos limites da moral (PRADO Jr., 1996). Quando nosso proto-arqueólogo considera essa religião como uma que dá mais vasão à pulsão da natureza, ele assume também que esse ato sexual não necessariamente seja negativo ou degradante, mas que em alguma medida seja também um dever do corpo.

Com efeito, há uma certa contradição patente na forma como Hancarville se posiciona sobre a moral sexual de modo mais genérico. Como vimos, por um lado ele considera a licença erótica dos antigos uma mostra das mudanças negativas que a cultura grega trouxe para Roma. Em outros momentos do texto, percebemos que a compreensão do sexo dos antigos surge como uma forma de criticar também a modernidade. Se eles não tinham culpa dos atos que cometiam por motivo de seus deuses, os modernos o tem já que seu deus não permite o sexo, o que torna tudo muito mais ilícito e, portanto, os atos mais hediondos:

Nous sommes donc bien injustes, lorsque nous regardons les beaux siecles de la Grece \& de Rome, comme étant ceux de la plus haute dépravation. Et si nous

\footnotetext{
${ }^{8}$ Os antigos não percebiam os prazeres do amor com o mesmo olhar que nós. Essa tenra união dos dois sexos excitava a veneração deles, porque a religião parecia consagrar esse ato da Natureza. A mitologia deles fornece e celebra muitos prodígios em amor. Júpiter, o pai dos deuses, irmão e esposo de Juno, estendia ainda suas conquistas amorosas em todo o universo. Leda, Europa, Dânae, Sêmele, Alcmena e mil outras belas mortais foram objeto de seus desejos e cederam a seu poder.
} 
comparons ces siecles avec le nôtre, eu égard aux idées religieuses \& morales qui dominaient alors, nous conviendrons sans peine, que le siecle present est infiniment plus corrompu. En effet, à quel degré, à quel excès de dépravation ne serions-nous pas parvenus, si nos Divinités ne nous présentaient que des exemples licencieux, si notre culte, no temples, nos Prêtres ne nous offraient journellement que des images, des idées que nous nommons obscenes, \& qui ne l'étaient point pour les anciens? ${ }^{9}$ (D'HANCARVILLE, 1784, p. xvii)

Entretanto, a noção de que o sexo seja natural faz o historiador pensar também que esse impulso sexual seja não apenas aceitável, mas, em alguma medida, desejável. Se a religião dos antigos lhes permitia mais do que o cristianismo, ela também os tornava mais próximos da natureza e mais compreensíveis com ela. Não é irrelevante perceber que ao final de seu texto, Hancarville demonstre uma última inquietação com relação à pulsão do gozo: por que o fogo que animava os impulsos romanos se extinguia na modernidade ou tratava tão mal agora os que são por ele assaltados?

Não há resposta para a inquietação do antiquista, mas ela nos comprova algo que se nos torna conclusivo. Ao repensar os textos da Antiguidade de modo literal, Hancarville, em lugar de meramente repetir julgamentos tradicionais da moral cristã, usou desses exemplos para questionar as relações que se estabeleciam entre a moralidade, a crença religiosa e o sexo no seu passado e no seu presente. Embora mantenha alguma moralidade - e cabe relembrar que nem todo libertino é favorável a levar a prática sexual ao seu extremo - esse proto-arqueólogo passa a pensar os próprios limites e justificativas para a moralidade de seu tempo. Apresentar representações sexuais antigas com uma justificativa compreensiva em relação às práticas pretéritas é não apenas criar um documento que poderia chocar seu tempo, mas também criar uma atitude de compreensão nos leitores, aceitar o passado e naturalizar em algo esse sexo, se nos é permitido um jogo de palavras. Marcada pelo enorme número de perguntas retóricas feitas por Hancarville em seus textos, a atitude do pensador com relação à Antiguidade é uma de inspiração e questionamento. Buscar aceitar e compreender as atitudes sexuais faz o passado surgir como uma das mostras dos limites positivos ou negativos que se estabelecem entre a moralidade cristã e os impulsos da libido. A sensação de perda que Hancarville expressa com relação a esse passado atesta o quanto esse intelectual desejava transformar, em algo, essa moralidade.

\section{À guisa de conclusão}

Como percebemos, estudar a relação de Hancarville com o passado antigo nos fez notar que esse escritor do século XVIII, antes mesmo do surgimento da arqueologia científica, estabelecia com o passado uma relação curiosa: ele o fazia surgir como diferença e, na tentativa de compreendê-lo, fazia essa diferença questionar seu próprio presente e ética. Com alguma ironia, Hancarville pode acusar seus contemporâneos de maior depravação que os antigos e mesmo incitá-los pensar uma relação mais "natural" com seus desejos ao mesmo tempo que expõe figuras de elevado valor erótico. Inspirado por problemas e proposições filosóficas libertinas, o uso feito por esse escritor

\footnotetext{
${ }^{9}$ Somos muito injustos ao olhar esses belos séculos da Grécia e de Roma como sendo aqueles da mais alta depravação. E se compararmos esses séculos ao nosso, considerando as ideias religiosas e morais que dominavam à época, conviremos sem dificuldade que o século presente é infinitamente mais corrompido. Com efeito, a que grau e a que nível de depravação não chegaríamos se nossas divindades só nos apresentassem exemplos licenciosos, se nosso culto, nossos templos, nossos padres somente oferecessem, diariamente, imagens, ideias que chamamos de obscenas e que não o eram à época?
} 
do passado difere, em muito, dos usos mais comumente estudados pelos autores que debatem os usos do passado e que mencionamos no primeiro momento de nosso texto. Nesse caso, o pretérito não necessariamente se aproxima de um poder institucional nem da criação de um estado nacional. Ao contrário, Hancarville nunca conseguiu acesso aos locais de estudo instituídos pela coroa napolitana, e teve seus estudos e publicações garantidas pela proximidade com Hamilton e um ciclo de pensadores ingleses também ricos e interessados pela Antiguidade. Embora não estivesse nas classes baixas, Hancarville é mostra de um conhecimento menos institucionalizado.

Mas nosso objetivo com os estudos dos usos do passado não era o de pensar uma relação entre o a historiografia e o poder, mas sim o de perceber modos diferentes de se relacionar com o pretérito e, ao mesmo tempo, buscar uma maior polifonia na história. Esse personagem nos faz entender um modo menos autoritário de relação com a Antiguidade, um no qual ela era o outro que questiona a Modernidade. Apesar de vermos monumentos inventados por Hancarville, notamos que seu trabalho com a documentação antiga era algo sério e bem fundamentado - todos os seus textos emergem de referências antigas bem expressas e de um profundo conhecimento da documentação - apesar de balizado por problemáticas diferentes da historiografia acadêmica mais tradicional. Mesmo sua interpretação sobre a religião é fruto de uma leitura profunda e de uma tentativa de generalização sobre o passado. Em que pese seu método próximo do de alguns dos primeiros historiadores da modernidade - a saber, o de limitar-se ao cotejo de fontes e leitura atenta delas - o silêncio no qual caiu sua obra tem muito a dizer sobre a própria formação da academia. No século XIX, a história dos imperadores antigos seria narrada por uma ciência já instituída e próxima aos interesses dos Estados Modernos. Associada, em muito, com a psicologia e com a scientia sexualis, as histórias dos doze primeiros césares de Roma serão, cada vez mais, narradas enquanto histórias de loucura, depravação e de degradação da cultura (e. g. MORALI-DANINOS, 1963). Taxado de demência, esse passado será preso a uma narrativa de inspiração cada vez mais cristã e moderna e, cada vez menos, ressurgirá com força de contestação. As práticas sexuais romanas serão enterradas no túmulo da história e Hancarville cairá no esquecimento, inspirando uma leitura da sexualidade como elemento natural de uma cultura que apenas terá sobrevivência em outras obras de pensamento crítico e menos célebres, como as de Richard Payne Knight e, talvez, até em Geroges Bataille (cf. CARABELLI, 1996). A própria busca do passado enquanto instrumento para repensar o presente de maneira crítica parece ter ganhado força, principalmente, apenas da segunda metade do século XX em diante. Apesar do silêncio em que fora lançado, e que também mencionamos acima querer combater, talvez a leitura de Hancarville, tão erudita e provocadora, possa inspirar o surgimento de novas vozes, interpretações, usos e maneiras de perceber esse passado antigo.

\section{Referências}

ARNOLD, B. (1990). The past as propaganda: totalitarian archaeology in Nazi Germany. Antiquity, 64, 464-478.

CARABELLI, G. (1996). Veneri e Priapi: culti di fertilità e mitologie falliche tra Napoli e Londra nell'età dell'illuminismo. Ferrarra: Edição online da Universidade de Ferrarra. Retrieved Fevereiro 14, 2017, from http://www.unife.it/letterefilosofia/filosofia/allegati/allegati_annali/carabelli_annali.pdf. 
DARNTON, R. (1996). Sexo dá o que pensar. In A. NOVAES, Libertinos libertários (pp. 21-42). São Paulo: Companhia das Letras.

DAVIS, W. (2001). Homoerotic Art Collection from 1750 to 1920. Art History, 21(No 2), 247-277.

DERRIDA, J. (2017). Gramatologia. São Paulo: Perspectiva.

D'HANCARVILLE, P.-F. H. (1782). Monumens de la vie privée des douze Césars. Capre. Disponível em : https://gallica.bnf.fr/ark:/12148/bpt6k5525623c?rk=21459;2 acesso em 18/04/2019.

D'HANCARVILLE, P.-F. H. (1784). Monumens du culte secret des dammes romaines. Capre. Disponível em: https://gallica.bnf.fr/ark:/12148/bpt6k55160418?rk=21459;2 acesso em 18/04/2019.

ECHLIN, A. (2014). Dynasty, Archaeology and Conservation: The Bourbon rediscovery of Pompeii and Herculaneum ineighteenth-century Naples. Journal of History of Collections, 26(No 2), 145-159.

FOUCAULT, M. (2011). História da sexualidade (Vol. 1 A vontade de saber). (M. T. Albuquerque, Trans.) São Paulo: Edições Graal.

FOWLER, D. D. (1987). Uses of the Past: Archaeology in the service of the State. American Antiquity, 52, 229-248. Retrieved 05 08, 2014, from http://www.jstor.org/stable/281778.

FUNARI, P. P., Silva, G. J., \& GARRAFFONI, R. S. (2017). Posfácio: Usos do passado e recepção: um debate. In G. J. SILVA, R. S. GARRAFFONI, P. P. Funari, J. GRALHA, \& R. (. Rufino, Antiguidade como Presença: antigos, modernos e os usos do passado (pp. 313-314). Curitiba: Prismas.

GRILLO, J. G. (2018). A imaginação do passado e a construção da identidade grega: o caso da arqueologia clássica no século XIX. In G. J. SILVA, R. S. GARRAFFONI, P. P. Funari, J. GRALHA, \& R. Rufino, Antiguidade como presença: antigos, modernos e os usos do passado (pp. 185-193). Curitiba: Prismas.

HERING, F. A. (2005). Arqueologia e nacionalismo na Europa no séxulo XIX: a Grécia antiga e sua reativação moderna. In P. P. FUNARI, C. E. ORSER Jr, \& S. N. SCHIAVETTO, Identidades, discurso e poder: Estudos da arqueologia contemporânea (pp. 147-158). São Paulo: Annablume.

HINGLEY, R. (2017). Contribuições a uma arqueologia de Roma pós- colonial: ligando Brasil e Grã-Bretanha. Heródoto, 2, p. 104-113. doi:http://dx.doi.org/10.31669/herodoto.v2i2.267.

HUWILER, M. (2015). De Naples à Londres: destin de la première collection Hamilton. In P.-F. H. D'HANCARVILLE, The complete collection of antiquities from the Cabinet of Sir William Hamilton (pp. 52-55). Colônia, Alemanha: Taschen.

JAUSS, H. R. (1994). A História da Literatura como provocação à Teoria Literária. (S. Tellaroli, Trans.) São Paulo: Editora Ática.

JOYCE, R. (2006). Writing historical archaeology. In D. HICKS, \& M. C. BEAUDRY, Historical Archaeology (pp. 48-65). Cambridge: Cambridge University Press. 
LITTLE, B. (2007). Historical Archaeology: why past matters. Walnut Creek: Lef Coast Press.

MINOIS, G. (2007). História do Riso e do Escárnio. São Paulo: Editora da Unesp.

MONOD, P. K. (2013). Solomon's secret art: the occult in the age of Enlightment. New Haven: Yale University Press.

MORALI-DANINOS, A. (1963). Histoire des Relations Sexuelles. Paris: P.U.F.

NOVAES, A. (1996). Para que tanta libertinagem? In A. NOVAES, Libertinos libertários (pp. 9-20). São Paulo: Companhia das Letras.

PEREIRA, B. C., \& Esteves, A. M. (2016). Calígula: conflitos entre o imperador e a aristocracia. In A. M. ESTEVES, L. F. ASSUMPÇÃO, \& R. d. NOGUEIRA, Líderes políticos da Antiguidade (pp. 327-345). Rio de Janeiro: Desalinho Publicações e Pórtico.

PRADO Jr., B. (1996). A filosofia das luzes e as metamorfoses do espírito libertino. In A. Novaes, Libertinos libertários (pp. 43-57). São Paulo: Companhia das Letras.

PREVOT, J. (1998). Libertins du XVIle siècle. Paris: Gallimard (Bibliothèque de la Pléiade).

PUCCINI, G. (2007). La vie sexuelle à Rome. Paris: Éditions Tallandier.

RUFINO, R. A. (2013). O Bimilenário de Augusto na Espanha (1939-1940): As construções discursivas do franquismo sobre a Antiguidade romana. Campinas: Dissertação defendida como requisito para obtenção do diploma de Mestre em História pelo Instituto de Filosofia e Ciências Humanas.

SCHNAPP, A. (2000). Antiquarian Studies in Naples at the end of the eighteenth century. From comparative archaeology to. In G. IMBRUGLIA, Naples in the Eighteenth Century: the birth and death of a NationaState (pp. 154-167). Cambridge: Cambridge University Press.

SCHÜTZE, S. (2015). Antiquités étrusques, grecques et romaines tirées du Cabinet de M. Hamilton. In P.-F. H. D'HANCARVILLE, The complete collection of antiquities from the cabinet of Sir William Hamilton (pp. 30-52). Colônia, Alemanha: Taschen.

\section{Notas de autoria}

Alexandre Cozer, doutorando no Programa de Pós-Graduação em História pela Universidade Federal do Paraná. Possui graduação e mestrado pela mesma instituição. Bolsista CNPq até 01/2019. Professor de História no Colégio Suíço-Brasileiro de Curitiba. E-mail: cozeralexandre@gmail.com

\section{Como citar esse artigo de acordo com as normas da revista}

COZER, Alexandre. O libertino e os usos do passado antigo: ensaio sobre a relação de Hancarville com o passado Romano (1780). Sæculum - Revista de História, v. 24, $\mathrm{n}^{\circ}$ 41, p. 82-98, 2019.

\section{Contribuição de autoria}

Não se aplica.

\section{Consentimento de uso de imagem}

Não se aplica. 
Aprovação de comitê de ética em pesquisa

Não se aplica.

\section{Licença de uso}

Este artigo está licenciado sob a Licença Creative Commons CC-BY. Com essa licença você pode compartilhar, adaptar, criar para qualquer fim, desde que atribua a autoria da obra.

\section{Histórico}

Recebido em 20/04/2019.

Aprovado em 29/08/2019. 